\title{
Electro-osmotic driven flow of Eyring Powell nanofluid in an asymmetric channel
}

\author{
Vijayaragavan $\mathrm{R}^{1}$, Tamizharasi $\mathrm{P}^{1}$, and Magesh $\mathrm{A}^{2}$ \\ ${ }^{1}$ Thiruvalluvar University \\ ${ }^{2}$ Jei Mathaajee College of Engineering
}

August 24, 2021

\begin{abstract}
This article aims to investigate the numerical study of electroosmotic flow of the Eyring Powell fluid under the peristaltic mechanism with the influence of the porous medium in the micro-channel. The modified system is applied externally to an electrical field in the horizontal direction and to a magnetic field in the transverse direction. The flow of nanofluids is considered in the computation. The governing equations in the nano-fluid flow are modulated. Influence of lubrication theory approximation longequations are shortened. Reduced coupled nonlinear partial differential equations like velocity and energy equations are numerically solved using the powerful and well-known mathematical software MATHEMATICA by built in NDSolve command. The influence of various important parameters on the velocity and temperature profile is summarised by graphs.
\end{abstract}

\section{Hosted file}

manuscript.docx available at https://authorea.com/users/431605/articles/535102-electroosmotic-driven-flow-of-eyring-powell-nanofluid-in-an-asymmetric-channel

\section{Hosted file}

diagram.docx available at https://authorea.com/users/431605/articles/535102-electro-osmoticdriven-flow-of-eyring-powell-nanofluid-in-an-asymmetric-channel 